\title{
Multivariate Analysis of Cashew (Anacardium occidentale L.) Germplasm in Nigeria
}

\author{
By O. M. AliYu' ${ }^{1), *}$ and J. A. Awopetu' ${ }^{2)}$
}

(Received $2^{\text {nd }}$ May 2006)

\begin{abstract}
Multivariate analyses were carried out on fifty-nine germplasm accessions of cashew derived from both local and exotic populations established at the research plots of Cocoa Research Institute of Nigeria (CRIN), Ibadan, southwestern Nigeria, to assess the extent of variability and pattern of genetic diversity among these cashew populations. Data collected on 36 quantitative and 33 qualitative plant characters were subjected to taximetric tools of Euclidean distance of complete linkage (furthest neighbour) and principal component analysis (PCA).

The multivariate analyses tentatively grouped the selections into four distinct morphogenetically diverse clusters. The groupings appear to be a function of origin, eco-geographical distribution, genetic and/or agronomic affinity of the selections. Brazilian populations distinctly clustered together in two major groups while local clones and Indian selections dominated the other two major clusters with each group having its unique fruiting and tree growth habits. The clustering pattern at sub-cluster levels clearly reflects affinity of each genetic population. The principal component analysis and the potency indices showed that fruit characters are the most discriminating parameters for delineating cashew at the varietal level.
\end{abstract}

Key words: Accessions, Anacardium occidentale, genetic variability.

\section{Introduction}

Cashew is an important tropical fruit crop that originated from South American countries like Bolivia, Brazil, Ecuador and Peru (VAlvilov, 1951; BeHRENS 1998) and is widely cultivated in tropical regions of the world. Cashew production is centralized in Third World countries and major producers of cashew nuts are India, Tanzania, Mozambique, Nigeria, Guinea-Bissau and Kenya. In 2002, major producers of cashew nuts are India (460,000 tonnes), Nigeria (186,000 tonnes), Brazil (178,000 tonnes) and Tanzania (123,000 tonnes) (FAO, 2004). The crop was introduced from Brazil into Nigeria by Portuguese adventurers during the $16^{\text {th }}$ century (Venkataramah, 1976; Mitchell and Mori, 1987). Initially, the trees were mainly planted for afforestation

\footnotetext{
$\left.{ }^{1}\right)$ Department of Plant Breeding and Genetics, Cocoa Research Institute of Nigeria, P. M. B. 5244, Ibadan, Nigeria. E-mail: walealiyu@mail.com.

$\left.{ }^{2}\right)$ Department of Agronomy, University of Ilorin, P. M. B. 1515, Ilorin, Nigeria.

*) Corresponding Author. Present address of corresponding author: Department of Cytogenetics and Genome Analysis, Leibniz Institute of Plant Genetics and Crop Plant Research (IPK), Corrensstraße 3, D-06466 Gatersleben Germany. E-mail: aliyu@ipk-gatersleben.de.
}

and erosion control especially in the former eastern region of Nigeria with sloppy topography. The crop however became an important plantation crop in the $1950 \mathrm{~s}$ with the establishment commercial plantations at Oghe, Oji, Udi and Mbala in the old eastern Nigeria by the Eastern Nigerian Development Corporation (ENDC) and at Iwo, Eruwa and upper Ogun in the old western Nigeria by the Western Nigerian Development Corporation (WNDC). Records showed that these plantations were planted to nuts introduced from India in the early 1950s (SANWO, 1974).

Little or no attention was given to cashew in Nigeria until 1971 when the Cocoa Research Institute of Nigeria (CRIN) was mandated to carry out genetic improvement in the crop species. Realizing the importance of genetic diversity as the raw materials for crop improvement as opined by ALLARD (1970) and BROwN (1989), the Institute embarked upon germplasm acquisition programme for local land race (clones) from farmer's fields and exotic Indian accessions from existing ENDC and WNDC's plantations (Togun, 1977; AKINWALE and EsAN, 1989). Between the period 1974 and 1978, CRIN introduced more genetic materials directly from India (SANwO, 1979). In spite of all these efforts, very little progress was achieved by CRIN in increasing cashew production in the 1980s and this was attributed to narrow genetic base of the introductions. This low production was clearly evident as annual cashew nut production in Nigeria ranged between 22,000 tonnes and 30,000 tonnes for the period 1965 to 1990 (FAO, 2004).

Broadening the genetic base by introducing new alleles present in exotic germplasm (FAENZA et al., 1982) and a systematic exploitation of heterosis (MASAWE, 1994) have been suggested as means to overcome some of the problem. As part of efforts to increase the genetic base of the cashew germplasm in Nigeria and consequently improving the crop, CRIN embarked upon an expedition in the mid-1980s and this led to acquisition of exotic Brazilian materials from a private commercial farm. These genetic materials were originally introduced from Brazil in 1982 by the farmer. It is expected that several introductions of genetic materials of different geographical origin and possible genetic introgression among materials that coexist for long time would have resulted into considerable variation in the cashew genetic resource in the country. Cashew improvement is however limited by the lack of adequate knowledge of genetic diversity of the existing germplasm of both local and exotic origin. MNENEY et al. (2001) opined that adequate knowledge and information about the genetic similarity of gene pool around the world is essential for the identification of parental lines in order to exploit heterosis and introduce valuable characters into the cashew 
breeding programme. The use of polymorphic markers has been recently promoted for identification of varieties and estimation of genetic similarity among populations (WILliAMs et al., 1990, ZiEGENHAGEN et al., 1993; KRABEL et al., 1998; CASAS et al., 1999). RAPD analysis has been used to study the genetic relationship in Indian cashew germplasm and has been found to corroborate the results obtained from morphogenetic marker study (DHANARAJ et al., 2002 SAMAL et al., 2003). SAMAL et al. (2003) however remarked that classical phenotype features are still extremely useful; although the efficiency of selection may be influence by developmental stages or by environmental effects on measured traits. Environmental influence can be minimized by appropriate experimental breeding design. Moreover, breeding of cashew is mostly based on traditional methods of selection of useful traits which are basically phenotypic like nut size, nut weight, sex ratio, length of panicle and yield performance (MNENEY et al., 2001). The choice of phenotypic markers in this study was informed by its possible practical implication on cashew breeding programme and immediate impacts on the poor resource farmers in a third world country like Nigeria. However, BRown (1989) opined that an important way to increase productivity in any crop plant is to assess the genetic diversity in order to select desirable genotypes from the existing variants and to use the superior types in breeding programme. Therefore, it becomes imperative to quantify the extent of variation among the cashew germplasm collections in Nigeria by using phenotypic markers. Edgar Anderson pioneered the use of quantitative analysis in evaluating genetic affinity in crop species (Awopetu, 1982). However, SNEATH and SoKaL (1973) reported that attempts at a numerical consideration of taxonomic relationships dated back to more than 200 years, but that integrated approaches to this technique has been intensified in the last few decades. Details on such developments are available in SOKAL and Sneath (1963), Sneath and Sokal (1973), Clifford and STEPHENSON (1975).

Table 1. - List of the 59 Cashew accessions and their pedigree.

\begin{tabular}{|c|c|c|c|c|c|c|c|}
\hline S/No. & $\begin{array}{l}\text { Accessi } \\
\text { on No. }\end{array}$ & $\begin{array}{l}\text { Original site of } \\
\text { collection }\end{array}$ & $\begin{array}{c}\mathrm{New} \\
\text { Site } \\
\text { planted }\end{array}$ & S/No & $\begin{array}{l}\text { Accession } \\
\text { No. }\end{array}$ & $\begin{array}{l}\text { Original site } \\
\text { of collection }\end{array}$ & New Site planted \\
\hline 1 & $\mathrm{CC} 01$ & Ochaja & CRIN Ibadan & 31 & CSI62 & $\begin{array}{c}\text { India/WNDC } \\
\text { Iwo }\end{array}$ & CRIN Ibadan \\
\hline 2 & $\mathrm{CC} 02$ & $"$ & $"$ & 32 & CSI63 & $"$ & $"$ \\
\hline 3 & $\mathrm{CC} 03$ & $"$ & $"$ & 33 & CSI66 & $"$ & $"$ \\
\hline 4 & $\mathrm{CC} 04$ & $"$ & $"$ & 34 & CSI67 & $"$ & $"$ \\
\hline 5 & $\mathrm{CC} 05$ & $"$ & $"$ & 35 & $\mathrm{CSO} 01$ & Brazil & $"$ \\
\hline 6 & $\mathrm{CC} 06$ & $"$ & $"$ & 36 & $\mathrm{CSO} 02$ & $"$ & $"$ \\
\hline 7 & $\mathrm{CC} 07$ & $"$ & $"$ & 37 & $\mathrm{CSO} 03$ & $"$ & $"$ \\
\hline 8 & $\mathrm{CC} 08$ & $"$ & $"$ & 38 & $\mathrm{CSO} 04$ & $"$ & $"$ \\
\hline 9 & $\mathrm{CC} 09$ & $"$ & $"$ & 39 & CSO05 & $"$ & $"$ \\
\hline 10 & $\mathrm{CC} 10$ & $"$ & $"$ & 40 & CSO06 & $"$ & $"$ \\
\hline 11 & $\mathrm{CC} 11$ & $"$ & $"$ & 41 & $\mathrm{CSO} 07$ & $"$ & $"$ \\
\hline 12 & $\operatorname{CSI} 00$ & India/WNDC Iwo & $"$ & 42 & $\mathrm{CSO} 08$ & $"$ & $"$ \\
\hline 13 & CSI01 & $"$ & $"$ & 43 & CSO09 & $"$ & $"$ \\
\hline 14 & CSI05 & $"$ & $"$ & 44 & $\mathrm{CSO} 10$ & $"$ & $"$ \\
\hline 15 & CSI06 & $"$ & $"$ & 45 & CSO11 & $"$ & $"$ \\
\hline 16 & CSI07 & $"$ & $"$ & 46 & $\mathrm{CSO} 12$ & $"$ & $"$ \\
\hline 17 & CSI09 & $"$ & $"$ & 47 & $\mathrm{CSO} 13$ & $"$ & $"$ \\
\hline 18 & CSII0 & $"$ & $"$ & 48 & CSO14 & $"$ & $"$ \\
\hline 19 & CSII1 & $"$ & $"$ & 49 & CSO15 & $"$ & $"$ \\
\hline 20 & CSI13 & $"$ & $"$ & 50 & CSO16 & $"$ & $"$ \\
\hline 21 & CSI14 & $"$ & $"$ & 51 & CSO17 & $"$ & $"$ \\
\hline 22 & CSI18 & $"$ & $"$ & 52 & CSO18 & $"$ & $"$ \\
\hline 23 & CSI23 & $"$ & $"$ & 53 & CSO19 & $"$ & $"$ \\
\hline 24 & CSI27 & $"$ & $"$ & 54 & $\mathrm{CSO} 20$ & $"$ & $"$ \\
\hline 25 & CSI30 & $"$ & $"$ & 55 & $\mathrm{CSO} 21$ & $"$ & $"$ \\
\hline 26 & CSI31 & $"$ & $"$ & 56 & $\mathrm{CSO} 22$ & $"$ & $"$ \\
\hline 27 & CSI36 & $"$ & $"$ & 57 & $\mathrm{CSO} 23$ & $"$ & $"$ \\
\hline 28 & CSI51 & $"$ & $"$ & 58 & $\mathrm{CSO} 24$ & $"$ & $"$ \\
\hline 29 & CSI58 & $"$ & $"$ & 59 & $\mathrm{CSO} 25$ & $"$ & $"$ \\
\hline 30 & CSI61 & $"$ & $"$ & & & & \\
\hline
\end{tabular}


Table 2. - List of 36 quantitative characters and their acronyms.

\begin{tabular}{|c|c|c|c|}
\hline Characters & Acronyms & Characters & Acronyms \\
\hline Weight of whole fruit $(\mathrm{g})$ & WWF & Kernel weight $(\mathrm{g})$ & KWH \\
\hline Apple weight $(g)$ & AWT & Kernel to nut ratio & KNR \\
\hline Apple length $(\mathrm{cm})$ & ALT & Volume of CNSL/nut & $\mathrm{VCN}$ \\
\hline Apple upper circumference $(\mathrm{cm})$ & AUC & Number of flowers per panicle & FPP \\
\hline Apple lower circumference $(\mathrm{cm})$ & ALC & Number of male flowers per panicle & MPP \\
\hline Apple fluid weight $(\mathrm{g})$ & AFW & Number of hermaphrodite per panicle & HPP \\
\hline Apple dry weight (g) & $\mathrm{ADW}$ & Number of abnormal flowers & APP \\
\hline Nut weight (g) & NWT & Flower sex ratio & FSR \\
\hline Number of nut per panicle & NNP & Percentage pollen stainability & PPS \\
\hline Total nut yield per tree & NYT & Percentage pollen germination & PPG \\
\hline Number of nut per tree & NNT & Pollen grain size (um) & PGS \\
\hline Nut length $(\mathrm{cm})$ & NLT & Tree crown spread (m) & TCS \\
\hline Nut lower width $(\mathrm{cm})$ & NLW & Tree trunk circumference & $\mathrm{TCM}$ \\
\hline Nut upper width $(\mathrm{cm})$ & NUW & Number of leaves per twig & LTW \\
\hline Nut lower length $(\mathrm{cm})$ & NLL & Tree height (m) & THT \\
\hline Nut upper length $(\mathrm{cm})$ & NUL & Days to $50 \%$ flower Anthesis & DFA \\
\hline Nut thickness (cm) & NTK & Days to $50 \%$ fruit maturity & DFM \\
\hline Shell weight (g) & SWH & Harvesting Period & HPD \\
\hline
\end{tabular}

Table 3. - List of 33 qualitative characters and their acronyms.

\begin{tabular}{llll}
\hline Character & Acronyms & Character & Acronyms \\
\hline Apple colour & ACL & Colour of CNSL & CNL \\
Apple ridges & ARG & Leaf shape & LSH \\
Apple skin texture & AST & Leaf size & LSZ \\
Apple shape & ASH & Shape of leaf apex & LAS \\
Apple cavity atapex & ACA & Angle of leaf petiole to stem & ALP \\
Apple apex & APA & Branching pattern & BPT \\
Apple base & ABS & Colour of young leaves & CYL \\
Apple juice astringency & AJA & Colour of mature leaves & CML \\
Nut shape & NSH & Crack on trunk bark & CTB \\
Nut base shape & NBS & Crotch angle of main branch & CAM \\
Nut apex shape & NAS & Tree habit & THB \\
Suture relative position & SRP & Secondary flowering habit & SFH \\
Nut flank & NFK & Leaf margin & LMG \\
Nut stylar scar & NSS & Colour of boot leaves & CBL \\
Nut attachment to apple & NAA & Susceptibility to Inflorescence blight & SIB \\
Nut suture & NSU & Susceptibility to stem girdling & SSG \\
Colour of mature nut & CMN & & \\
\hline & & &
\end{tabular}


In the present study, multivariate analyses of Euclidean distance of complete linkage and principal component analysis (PCA) were employed in the analysis of phenotypic data of 59 cashew germplasm accessions of both local and exotic origins with the view to estimate genetic variability extant in this crop species in Nigeria.

\section{Materials and Methods}

Table 1 is a list of the experimental materials consisting of both local and exotic biotypes of cashew established at the research plots of the Cocoa Research Institute of Nigeria (CRIN), Ibadan (Lat. $07^{\circ} 10^{\prime} \mathrm{N}$, Long. $03^{\circ} 52$ 'E) southwestern Nigeria. The local accessions were eleven clones selected from farmer's farms in Ochaja, Kogi State (guinea savannah ecology), while the exotic accessions comprise twenty-three and twenty-five Indian and Brazilian introductions respectively. The farmer's clones are the materials selected from the early introductions of which the origin cannot be ascertained (SANwo, 1980). Meanwhile, the Indian selections are the open pollinated progenies of the materials originally introduced by the Eastern and Western Nigerian governments in the 1950 s for its plantations, while the Brazilian materials was introduced from Brazil by Kosoni-Ola Farms Limited, Oro, Kwara State in 1982. All the materials were planted at present location (CRIN, Ibadan) in 1987. The age of the trees was about 12 years at the inception of this study. The trees were planted at spacing of $10 \mathrm{~m} \times 10 \mathrm{~m}$ in randomized complete block design (RCBD) layout with three replications. Each accession was represented by three entries per block. Routine maintenances were carried out on the experimental plots. Table 2 and 3 show the list of selected characters used for data collection based on the Cashew Descriptor of the International Board for Plant Genetic Resources (IBPGR 1986). The data collected for 3 years (1999, 2000 and 2001) were subjected to cluster analyses, using taximetric principle of Euclidean distance complete linkage (furthest neighbour) and the principal component analysis. Analyses were performed using the N.T.S.Y.S. PC package version 1.8 (RHOLF, 1989).

\section{Results}

Figure 1 shows the dendogram from Euclidean distance of complete linkage clustering method as a measure of the extent of genetic relationships among the cashew accessions. Table 4 is the corresponding cluster and sub-cluster derivatives from figure 1. The dendogram shows similarity indices ranging between $22.00 \%$ and $100.00 \%$. At $62.00 \%$ similarity level, the dendogram group the 59 accessions to four main clusters similar to the result of principal component analysis (PCA) as shown in Figure 2. The summary characteristics of the groups and their respective means are presented in Table 5.

\section{Group I}

Thirteen accessions of Brazilian origin clustered in this group, but further divided into two sub-clusters (A

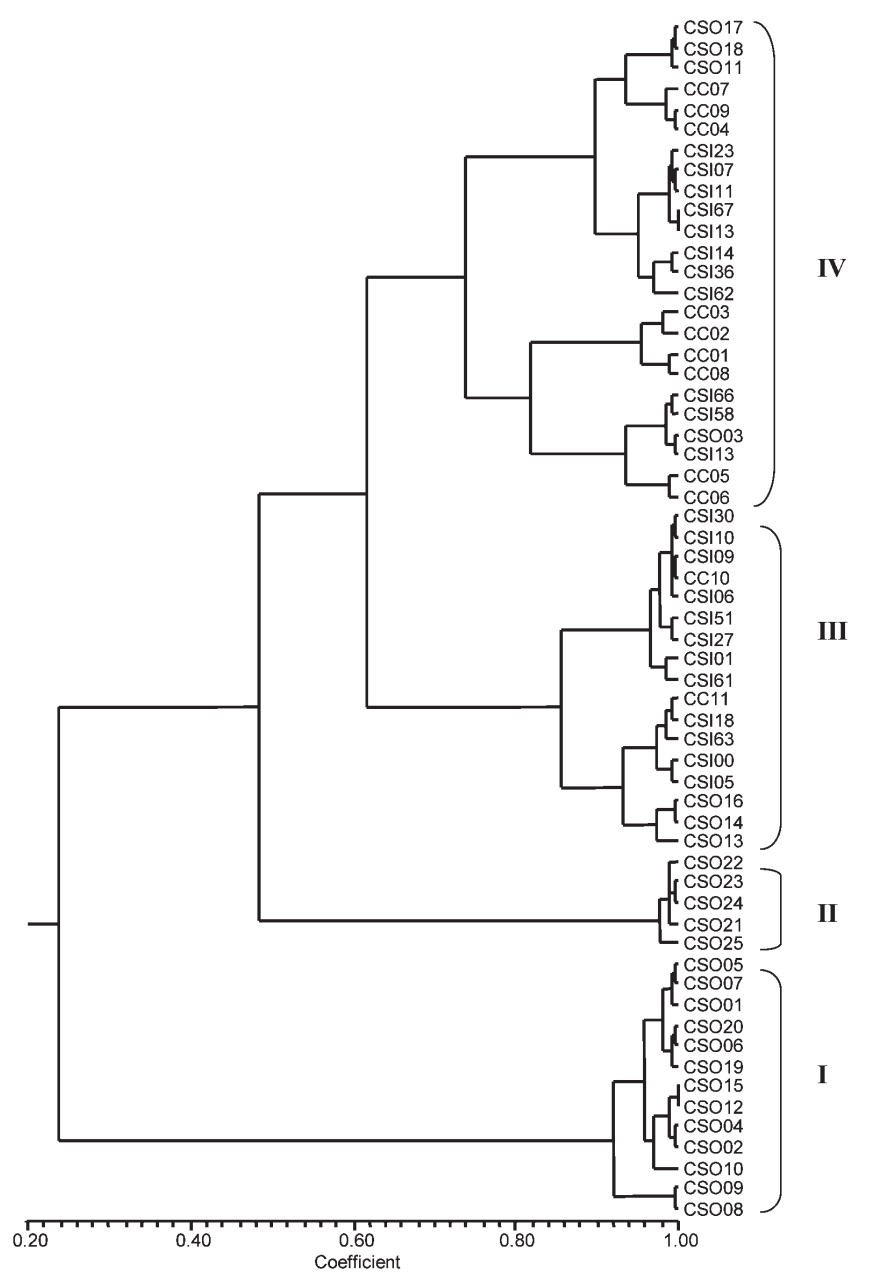

Figure 1. - Complete linkage dendogram showing the relationships among the fifty-nine cashew accessions.

and B) of 2 and 11 accessions respectively. These are mostly Brazilian accessions exemplified by large apple and medium-large sized nuts. They are characteristically early and high yielding with determinately intensive branching resulting into large open canopies. The apple produces high contents of juice and dry matter. Higher nut yield both in terms of number of nuts per tree and kilograme/tree was recorded in these trees despite few clustering of about 3 fruits per panicle and this can be linked to the prolific flowering and highly fertile pollens among these selections. They produce nuts with high content of kernel to nut ratios and moderate quantity of cashew nut shell liquid (CNSL). Period of fruit harvest among these accessions is short and no incidence of inflorescence blight and stem girdling was recorded in this group. The potentials abound in this set of trees suggest possible selection of high yielding varieties of cashew that produce high quality grade nuts in the short term for the poor resource cashew farmers. These materials will also be useful in any cashew improvement work among major producing countries in the West and East Africa sub-regions.

\section{Group II}

Five Brazilian accessions clustered together in this group. They are made up of jumbo-sized apple and nut 
Table 4. - Summary of the major clusters and sub-clusters of 59 cashew accessions derived from multivariate analyses.

\begin{tabular}{|c|c|c|}
\hline Cluster No. & Sub-clusters & List of accessions. \\
\hline \multirow[t]{2}{*}{ I } & $\mathrm{A}$ & CSO08, CSO09. \\
\hline & B & $\begin{array}{l}\text { CSO10, CSO02, CSO04, CSO12, CSO } 15 \text {, } \\
\text { CSO19, CSO06, CSO20, CSO01, CSO07, } \\
\text { CSO05. }\end{array}$ \\
\hline II & $\mathrm{C}$ & $\mathrm{CSO} 25, \mathrm{CSO} 21, \mathrm{CSO} 24, \mathrm{CSO} 23, \mathrm{CSO} 22$. \\
\hline \multirow[t]{2}{*}{ III } & $\mathrm{D}$ & $\begin{array}{l}\text { CSO13, CSO16, CSO14, CSI05, CSI00, } \\
\text { CSI63, CSI18, CC11. }\end{array}$ \\
\hline & $\mathrm{E}$ & $\begin{array}{l}\text { CSI61, CSI01, CSI27, CSI51, CSI06, } \\
\text { CC10, CSI09, CSI10, CSI30. }\end{array}$ \\
\hline \multirow[t]{4}{*}{ IV } & $\mathrm{F}$ & $\mathrm{CC} 06, \mathrm{CC} 05, \mathrm{CSI} 31, \mathrm{CSO} 03, \mathrm{CSI} 58, \mathrm{CSI} 66$ \\
\hline & G & $\mathrm{CC} 08, \mathrm{CC} 01, \mathrm{CC} 02, \mathrm{CC} 03$. \\
\hline & $\mathrm{H}$ & $\begin{array}{l}\text { CSI62, CSI36, CSI14, CSI13, CSI67, } \\
\text { CSI11, CSI07, CSI } 23 .\end{array}$ \\
\hline & I & $\begin{array}{l}\mathrm{CC} 04, \mathrm{CC} 09, \mathrm{CC} 07, \mathrm{CSO} 11, \mathrm{CSO} 18, \\
\mathrm{CSO} 17 .\end{array}$ \\
\hline
\end{tabular}

accessions with a great deal of dry matter content but low juice astringency. They produce few fruits per panicle but large shell and kernel ratios. They contain high level of cashew nut shell liquid (CNSL) and longspanned fruiting habits. The trees of these accessions produce very large leaves and exhibited spreading growth habit with extensive branching characteristic. The selections produce inflorescences with few staminate and hermaphrodite flowers and their pollen grains are large with moderate fertility. A nut yield in terms of nuts per tree was very low and this is probably due to large fruit size. These materials would be good source of genes that could be exploited in any improvement work to improve on fruit size and quality. The trees also offer potential for the future growing of cashew for the purpose of juice and other derivatives productions. These trees would be useful source of materials for genetic study to understand the nature of genes responsible for fruit and agronomic traits in cashew. The potentials within these germplasm stocks would only be useful for the long term breeding programme in cashew.

\section{Group III}

Two sub-clusters (D and E) were generated by this group and it contains a total of seventeen accessions of different geographical origins, however, it was predominated by the Indian selections with twelve entries. Only two local clones were recorded in this cluster. Three Brazilian accessions that exist within this group fused together at the same linkage level as a sub-cluster suggesting the extent of genetic similarity. Cashew accessions in this group and sub-groups generally produce small but many fruits per panicle. Suffice that the trees produce high number of nuts per tree but the average nut weight was very small, and this resulted into low total output in kilograme. Red apple with round shape is predominant among these trees. Other traits of this group are profuse flowering, very low CNSL and low apple dry matter contents. The apple juice content is also low but highly astringent. They produce small pollen grains that are highly fertile. The trees produce small leaves but with characteristic compact canopies 
and mostly mid-season producers that had moderatespanned fruiting habits. Pockets of trees with secondary flowering habit were noticed in this group. Moderate incidence of inflorescence blight and stem girdling were recorded among these accessions. The prolific flowering and fruiting habit and compact nature of the canopy could be exploited in future breeding work.

\section{Group IV}

It is heterogeneous group of the three selected populations. 9 of the eleven local clones were found within this group and this probably suggests high level of genetic introgression among these materials over the period of time. Only four Brazilian accessions fused in the group while the eleven others were Indian introductions. The clustering pattern of accessions within the group depicts origin and breeding history as the farmers' clones and Brazilian accessions fused together respectively. These trees produce the highest over all nut yield $(\mathrm{kg})$ per tree resulting from prolific fruiting and nut yield per tree. They are characteristically tall and upright trees with regular flowering and fruiting habits. High pollen grain fertility and very high flower sex ratios corroborate the prolific fruiting of these selections. The level of adaptation of these long introduced genetic materials was reflected in their yield performance.

\section{Principal Component Analysis (PCA)}

Figure 2 shows the principal component analysis (PCA) of the cashew accessions with the aid of the first two principal component axes which accounted for about $33.20 \%$ of the total variation. The divergent spread of the accessions across the PCA axes was similar to the four groups derived in the dendogram. The principal component analysis indicated the extent of genetic diversity of the selected cashew accessions based on the evaluated characters. The linear transformation performed by the principal component methods generated

Table 5. - Cluster means and description of some selected phenotypic traits showing variations among the 4 major groups derived from the multivariate analysis.

\begin{tabular}{|c|c|c|c|c|}
\hline Chara & Group I & Group II & Group III & Group IV \\
\hline Apple & & & & Min \\
\hline WWF (g) & 96.23 (large) & 178.89 (jumbo ) & 39.35 (small) & 75.22 (medium) \\
\hline $\mathrm{AWT}(\mathrm{g})$ & 85.32 (large) & 162.27 (jumbo) & 32.75 (small) & 67.47 (medium) \\
\hline $\mathrm{AFW}(\mathrm{g})$ & 80.12 (high) & 155.17 (very high) & 47.81 (low) & 61.33 (intermediate) \\
\hline $\mathrm{ADW}(\mathrm{g})$ & 5.05 (high) & 7.12 (high) & 1.92 (low) & 3.78 (intermediate) \\
\hline ACL & 1.15 (predominantly yellow) & 1.2 (predominantly yellow) & 1.96 (predominantly red) & 1.5 (mixture) \\
\hline ASH & 2.08 (conical-obovate) & 1.20 (predominantly cylindrical) & 3.11 (predominantly round) & 1.98 (predominantly cylindrical) \\
\hline AJA & 3.92 (low-slight) & 3.00 (low) & 6.94 (high) & 5.91 (high) \\
\hline \multicolumn{5}{|l|}{ Nut } \\
\hline NWT (g) & 9.91 (medium-large) & 16.81 (jumbo) & 4.04 (small) & 6.64 (small-medium) \\
\hline NNP & 2.93 (moderate) & 1.24 (low) & 8.15 (high) & 5.28 (high) \\
\hline NNT & 1446.14 (high) & 406.52 (low) & 1955.95 (high) & 1944.07 (high) \\
\hline NYT (kg) & 14.04 (high) & 7.82 (low) & 8.74 (low) & 13.30 (high) \\
\hline NTK $(\mathrm{cm})$ & 1.83 (large) & 1.95 (large) & 1.21 (small) & 1.62 (intermediate) \\
\hline SWH (g) & 5.52 (large) & 10.59 (very large) & 3.06 (small) & 4.21 (small-intermediate) \\
\hline KWH (g) & 4.27 (large) & 6.27 (very large) & 1.86 (small) & 2.28 (small-intermediate) \\
\hline $\mathrm{VCN}(\mathrm{ml})$ & 1.43 (high) & 1.98 (high) & 0.48 (low) & 0.85 (intermediate) \\
\hline NAA & 5.46 (intermediate) & 7.00 (tight) & 3.00 (loose) & 3.16 (loose) \\
\hline $\mathrm{CMN}$ & 3.15 (ash-grey) & 3.20 (ash-grey) & 2.17 (dark-grey) & 2.16 (dark-grey) \\
\hline \multicolumn{5}{|l|}{ Flora } \\
\hline FPP & 286.88 (high) & 54.69 (low) & 439.01 (high) & 398.86 (high) \\
\hline MPP & 239.67 (high) & 45.22 (low) & 244.11 (high) & 256.71 (high \\
\hline HPP & 52.04 (high) & 9.14 (low) & 59.57 (high) & 77.21 (high) \\
\hline APP & 0.15 (low) & 0.11 (low) & 0.28 (moderate) & 2.11 (high) \\
\hline FSR & 0.23 (moderate) & 0.21 (moderate) & 0.26 (moderate) & 0.43 (high) \\
\hline PPS & 80.73 (high) & 69.41 (moderate) & 87.63 (high) & 86.51 (high) \\
\hline PPG (um) & 37.26 & 29.92 & 37.18 & 36.40 \\
\hline PGS & 54.09 (large) & 61.02 (large) & 46.14 (small) & 50.20 (intermediate) \\
\hline \multicolumn{5}{|l|}{ Tree } \\
\hline $\operatorname{TCS}(\mathrm{m})$ & 9.92 (intermediate) & 13.79 (large) & 7.01 (small) & 10.74 (intermediate) \\
\hline $\mathrm{TCM}(\mathrm{m})$ & 1.11 (intermediate) & 1.38 (large) & 1.02 (intermediate) & 1.22 (intermediate large) \\
\hline LTW & 13.53 (High) & 10.60 (intermediate) & 15.20 (high) & 14.95 (High) \\
\hline THT $(\mathrm{m})$ & 9.55 (Intermediate) & 8.58 (intermediate) & 9.15 (intermediate) & 12.09 (Tall) \\
\hline CAM & 3.24 (acute) & 7.00 (obtuse) & 3.07 (very acute) & 3.50 (acute) \\
\hline SFH & 0.03 (very low) & 0.00 (absent) & 0.47 (present) & 0.12 (very low) \\
\hline BPT & 2.00 (intensive branching) & 1.00 (Extensive branching) & 2.00 (intensive branching) & 1.83 (intensive branching) \\
\hline THB & 5.00 (upright open canopy) & 7.00 (Spreading canopy) & 3.05 (Upright compact canopy & 5.33 (upright open canopy) \\
\hline SIB & 0.00 (no incidence) & 0.00 (no incidence) & 2.47 (low incidence) & 3.41 (moderate incidence) \\
\hline SSG & 0.00 (no incidence) & 0.00 (no incidence) & 2.58 (low incidence) & 3.66 (moderate incidence) \\
\hline \multicolumn{5}{|l|}{ Maturity } \\
\hline DFA & 71.92 (Early) & 211.20 (late) & 158.29 (mid-season) & 112.04 (Early/mid-season) \\
\hline DFM & 145.84 (Early and regular) & 283.40 (late and irregular) & $206.65 \mathrm{mid}$-season/long) & 194.71 (mid-season and regular) \\
\hline HPD & 24.62 (short) & 57.60 (long) & 40.00 (moderate) & 43.79 (moderate) \\
\hline
\end{tabular}


another 69 independent variables, known as principal components, which are described by their latent roots (Eigenvalues) and vectors (Tables 6 ). The latent roots associated with each principal component measures the contribution of each principal component to the total variance, while the coefficients of the latent vector associated with a given principal component indicate the degree of contribution (or loading) of each original variable to the principal component in question. RoJAs et al. (2000) stated that there has not been an established test for evaluating the significance of latent roots and therefore suggested the criterion established by KAISER (1960), as adapted in this investigation. According to this criterion, the first nineteen principal components qualify, accounting for about $96.17 \%$ of the total variation (Table 6) and this showed the trend of variation across the variables analyzed. The first four principal axes accounted for $50.14 \%$ of the variance.

Table 7 is the summary of the characters associated with the first four principal components and their degree of importance (potency index) of each variable. The nut characters (weight, number per panicle, number per tree, yield per tree, thickness, lengths of the lower and upper parts, shell weight, kernel weight and shelling percentage) dominated the first principal axis. However, apple characters (weight, length, circumfer- ences of the upper and lower parts, fluid/juice content and dry weight) mainly dominated the second principal axis. In addition to the quantitative characters with high positive component loads in the second principal component were colour and shape of the apple. However, third principal component $(8.82 \%)$ was associated with number of nuts per tree, total nut yield, number of nut per panicle, pollen grain fertility, and medium-sized nut. The component distinguished cashew accessions with very high clustering per panicle, high nut yield with high pollen grains fertility but the nuts are of mediumsized type. Other characters with high component loads were spread along principal components 5-15 with about $90.00 \%$ of the total variation. The spread of the variation across many principal component axis suggests that in genetic variability study involving identification of parental lines or varieties, phenotypic characters from fruit (nut and apple), floral, pollen and vegetative especially leaf, canopy type, tree habit and branching pattern should be selected.

\section{Discussion}

Generally, the similarity in the clustering patterns obtained among the two numerical techniques probably attest to the reliability of the methodology with respect

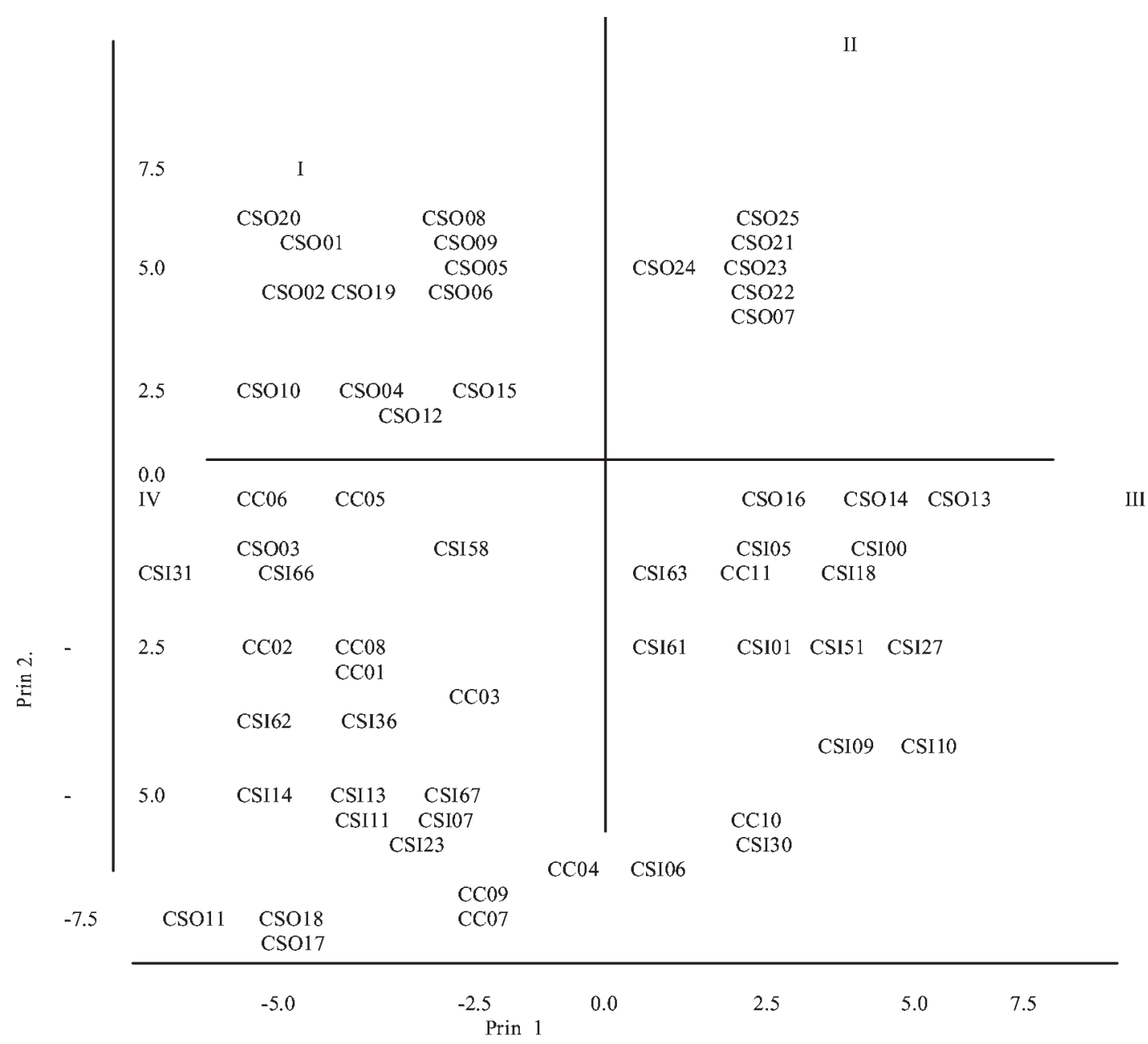

Figure 2. - The Principal Component Analysis (PCA) of the fifty-nine selected cashew accessions using the first two principal component axes. 
Table 6. - Eigenvalues of correlation matrix, the proportion and total variance for the first 20 principal component axes of the cashew accessions.

\begin{tabular}{|c|c|c|c|c|}
\hline Prin. & Eigenvalue & Difference & Proportion & Cumulative \\
\hline 1 & 14.68 & 3.72 & 0.18 & 0.18 \\
\hline 2 & 10.97 & 4.79 & 0.15 & 0.33 \\
\hline 3 & 6.18 & 0.75 & 0.09 & 0.42 \\
\hline 4 & 5.43 & 1.48 & 0.08 & 0.50 \\
\hline 5 & 3.94 & 1.03 & 0.05 & 0.56 \\
\hline 6 & 2.91 & 0.28 & 0.05 & 0.60 \\
\hline 7 & 2.63 & 0.21 & 0.04 & 0.64 \\
\hline 8 & 2.42 & 012 & 0.04 & 0.68 \\
\hline 9 & 2.31 & 0.23 & 0.03 & 0.71 \\
\hline 10 & 2.08 & 0.19 & 0.03 & 0.76 \\
\hline 11 & 1.89 & 0.22 & 0.03 & 0.78 \\
\hline 12 & 1.67 & 0.04 & 0.03 & 0.81 \\
\hline 13 & 1.63 & 0.18 & 0.03 & 0.83 \\
\hline 14 & 1.45 & 0.07 & 0.02 & 0.86 \\
\hline 15 & 1.37 & 0.11 & 0.02 & 0.88 \\
\hline 16 & 1.26 & 0.03 & 0.02 & 0.90 \\
\hline 17 & 1.23 & 0.06 & 0.02 & 0.92 \\
\hline 18 & 1.17 & 0.11 & 0.02 & 0.94 \\
\hline 19 & 1.06 & 0.09 & 0.02 & 0.96 \\
\hline 20 & 0.10 & 0.00 & 0.02 & 0.98 \\
\hline
\end{tabular}

to the collected data. The clustering pattern of the accessions probably reflects the genetic history, eco-geographical origins or collections, and/or agronomic affinity of the selections. The clustering of accessions on the basis of previous breeding history, geographical distribution and agronomic parameters was similar to the report of Swamy et al. (2002). Awopetu (1982) and Awopetu and ALIYU (2000), pointed out that entries from the same location might have evolved similar growth forms which often influence the pattern of fusion. Similar results have also been reported in Yam (CRUZ et al., 1999), Cocoa (LACHENAUD and OLIVER, 2001), Gerbera (ANURADHA and NARAYANA-GowDA, 2001), Lapsi (Choerospondias axillaries (Roxb.) B. L. BURTT and A. W. Hill) (PAUdEL et al., 2002).These submissions possibly lend credence to the fusion together of the accessions of Brazilian origin in groups 1 and 2 , and local selections in groups 3 and 4 of the dendograms. Nine sub-groups obtained from the dendograms represent morphogenetic variants of the four major groups on the basis of fruit (apple and nut), floral, fruiting, tree habit and leaf characteristics. Variation recorded among the selected accessions lends credence of the suggestion that population of a crop species from different ecological environment usually exhibit adaptive characteristics in morphological and agronomic traits (Allard, 1970; EDEMA and FAKOREDE, 1978). Such variants might have arisen from deliberate selection of preferred biotypes by farmers and consumers, changes connected with genetic aberrations (mutation) or gene transfer (introgression and hybridization), in addition to adaptation to local environment. The incidence of inflorescence blight disease and stem girdling insect recorded on cluster III and IV accessions that were dominated by local clones and Indian selections reflects the long 
Table 7. - Character associated with the first four principal components and their degree of importance (potency index) of each variable.

\begin{tabular}{|c|c|c|c|c|c|}
\hline Character & Prin. 1 & Prin. 2 & Prin. 3 & Prin. 4 & Potency Index \\
\hline \multicolumn{6}{|l|}{ Apple } \\
\hline WWF & 0.196 & $0.225^{*}$ & 0.106 & 0.064 & 0.521 \\
\hline AWT & 0.156 & $0.301 *$ & 0.108 & 0.028 & 0.482 \\
\hline ALT & 0.131 & $0.262 *$ & 0.136 & 0.042 & 0.391 \\
\hline AUW & $0.234^{*}$ & $0.281 *$ & 0.042 & 0.101 & 0.223 \\
\hline ALW & $0.228 *$ & $0.301 *$ & 0.112 & 0.046 & 0.212 \\
\hline ADW & 0.125 & $0.241 *$ & 0.136 & 0.020 & 0.394 \\
\hline AFW & 0.182 & $0.298^{*}$ & 0.105 & 0.112 & 0.401 \\
\hline ACL & $-0.204^{*}$ & $0.228 *$ & 0.045 & 0.105 & 0.361 \\
\hline ASH & 0.121 & $0.205^{*}$ & 0.124 & 0.084 & 0.296 \\
\hline \multicolumn{6}{|l|}{ Nut } \\
\hline NWT & $0.362 *$ & 0.080 & 0.056 & -0.050 & 0.791 \\
\hline NNP & $0.342 *$ & 0.010 & 0.107 & 0.041 & 0.464 \\
\hline NNT & $0.289 *$ & -0.021 & -0.097 & $0.234^{*}$ & 0.303 \\
\hline TYT & $0.239 *$ & 0.081 & -0.024 & -0.008 & 0.342 \\
\hline NTK & $0.250^{*}$ & 0108 & 0.053 & 0.038 & 0.240 \\
\hline NLL & $0.281 *$ & 0.056 & $0.321 *$ & 0.020 & 0.294 \\
\hline NLT & 0.062 & $0.205^{*}$ & 0.048 & -0.040 & 0.272 \\
\hline NUL & $0.293 *$ & -0.138 & 0.063 & -0.081 & 0.342 \\
\hline SWH & $0.299 *$ & -0.180 & $-0.338^{*}$ & 0.029 & 0.421 \\
\hline KWH & $0.323^{*}$ & 0.059 & $--0.224^{*}$ & 0.023 & 0.222 \\
\hline KSR & $-0.286^{*}$ & 0.031 & 0.198 & 0.054 & 0.262 \\
\hline $\mathrm{VCN}$ & 0.060 & 0.124 & $0.262^{*}$ & 0.041 & 0.223 \\
\hline \multicolumn{6}{|l|}{ Floral } \\
\hline FPP & 0.013 & -0.121 & $0.234^{*}$ & -0.101 & 0.351 \\
\hline MPP & 0.024 & -0.060 & $0.267^{*}$ & 0.024 & 0.323 \\
\hline HPP & 0.014 & -0.080 & $0.282 *$ & $0.373 *$ & 0.308 \\
\hline PPS & 0.063 & -0.138 & $0.269^{*}$ & 0.024 & 0.233 \\
\hline PPG & -0.070 & -0.077 & $0.339^{*}$ & 0.044 & 0.322 \\
\hline PGS & -0.162 & -0.035 & $0.232 *$ & $-0.302^{*}$ & 0.201 \\
\hline \multicolumn{6}{|l|}{ Vegetative } \\
\hline LTW & -0.116 & 0.188 & $-0.226^{*}$ & -0.041 & 0.142 \\
\hline TCS & -0.124 & 0.036 & 0.057 & $0.331^{*}$ & 0.139 \\
\hline THT & -0.052 & 0.061 & -0.020 & $-0.324 *$ & 0.182 \\
\hline TCM & -0.014 & 0.043 & -0.048 & -0.197 & 0.154 \\
\hline LSZ & $0.301 *$ & $0.200 *$ & 0.121 & 0.056 & 0.106 \\
\hline
\end{tabular}

* Characters with $\geq 0.200$ deviation.

history of introduction, adaptation and coexistence of the pests and the crop. It is important to note that the accessions from same regions tend to show similarity in some agronomic traits and this probably reflects the previous breeding history and adaptive genes that are resipotory in the selections. Yield quality characteristics such as, fruit size, nut yield, juice content and astringency, tree growth and branching pattern as well as flowering and fruiting habit, greatly influenced the clustering patterns of the accessions.

Major groups and sub-groups identified in this investigation are expected to enhance the selection of parents for use in breeding programme aimed at improving cashew production in Nigeria. EzEAKU and AwOPETU (1992) and Awoperu and Aliyu (2000) observed that crosses between groups and sub-groups are apt to generate more genetic variability than crosses within groups and sub-groups. It is also expected that knowledge of the groups and sub-groups identified may be used to develop cashew genotypes for specific purpose. The grouping of the accessions provides preliminary answer to the identification of parental lines for future breeding works on cashew in Nigeria and the proposed West Africa cashew improvement network programme. Similarly, the study also provide a short term solution to the identification of potential improved cashew varieties that combine high yielding with quality nut grade for the Nigerian cashew industry. The long term application of results of this study will greatly improve the quality of cashew nuts that will be produce for Nigerian cashew industry and global trade at large. The results also showed that the genetic base of Nigerian cashew has been enhanced and this effort will result in rapid improvement in the production of cashew in the country.

\section{References}

Akinwale, S. A. and E. B. Esan (1989): Advances in Cashew Breeding in Nigeria. In: Progress in Tree Crop Research. $2^{\text {nd }}$ Edition. Cocoa Research Institute of Nigeria, Ibadan, Nigeria, 166-174. 
AllaRD, R. W. (1970): Population Structure and Sampling Methods. In: Genetic Resources in Plants: Their Exploration and Conservation. O. H. FRANKEL and E. BENNETT (Eds.). I B P Handbook No. 11, Backwell Scientific Publication, Oxford, 97-107.

ANuradha, S. and J. V. NARAYANA-GowdA (2001): Characterization of gerbera (Gerbera jamesonii) genotypes using morphological characters. Plant Genetic Resources Newsletter 128: 64-67.

Awopeu, J. A. (1982): Genetic variability studies in Lupinus albus L. Ph. D Thesis, University of Reading, U. K.

Awopetu, J. A. and O. M. AliYu (2000): Genetic Diversity in Vigna unguiculata L. Walp. (Fabaceae). Moor Journal of Agricultural Research 1 (1): 22-31.

BEHRENS, R. (1998): About the spacing of cashew nut trees. Proceedings of International Cashew and Coconut Conference, 17-21 February 1997, Dar es Salaam, Tanzania. BioHybrid International Limited, U.K., pp. 48-52.

Casas, A. M., E. Lgartua, G. Balaguer and M. A. Moreno (1999): Genetic diversity of Prunus rootstocks analysed by RAPD markers. Euphytica 110: 139-149.

Clifford, H. T. and W. StePhenson (1975): An introduction of numerical classification. Academic Press, New York, San Francisco and London.

Cruz, V. M. V., N. C. Altroveros, M. S. Mendioro and D. A. RAMIREZ (1999): Geographical patterns of diversity in the Philippines edible yam collections. Plant Genetic Resources Newsletter 119: 7-11.

Dhanaraj, A., Rao E.V.V. Bhaskara, K. R. M. Swamy, M. G. Bhat, D. T. Prasad and S. N. Sondur (2002): Using RAPDs to assess the diversity in Indian cashew (Anacardium occidentale L.) germplasm. Journal of Horticultural Science and Biotechnology 77 (1): 41-47.

Edema, A. A. O. and M. A. B. FAKoredE (1978): Natural Variability in Horticultural Crops in Nigeria. Proceedings of $1^{\text {st }}$ Annual Conference of Horticultural Society of Nigeria, 123-138.

EzEAKU, I. E. and J. A. Awopetu (1992): A numerical analysis of variation patterns in some accessions of Soya bean (Glycine max.). Nigerian Journal of Botany $\mathbf{5}$ : 51-63.

IBPGR (1986): Descriptors for cashew (Anacardium occidentale L.) by International Board for Plant Genetic Resources, Rome, Italy, 33pp.

KAISER, H. F. (1960): The application of electronic computers to factor analysis. Educational and Psychological Measurement 20: 141-146.

Krabel, D., B. Vorman and S. Herzog (1998): PCR-based random amplification of genomic DNA from single pollen grains of tree. Angewandte Botanik 72: 10-13.

LACHENAUD, PH. and G. OLIVER (2001): Variability in various agronomic traits of wild cocoa trees (Theobroma cacao L.) from the Campoi and Tanpok basins. Plant Genetic Resources Newsletter 128: 35-40.

MASAWE, P. A. L. (1994): Aspect of breeding and selecting improving cashew genotypes (Anacardium occidentale L.). Ph. D. Thesis, University of Reading, UK.

Mitchell, J. D. and S. A. MoRI (1987): The cashew and its relatives (Anacardium, Anacardiaceae). Memoirs of New York Botanical Gardens English 42: 1-76.
Mneney, E. E., S. H. MANTELl and M. Bennett (2001): Use of random amplified polymorphic DNA (RAPD) markers to reveal genetic diversity within and between populations of cashew (Anacardium occidentale L). Journal of Horticultural Science and Biotechnology 76: 375-383.

Paudel, K. C., K. Pieber, R. Klumpp and M. Laimer DA Camara Machado (2002): Collection of germplasm of Lapsi (Choerospondias axillaries (Roxb.) B. L. BuRTT and A. W. HiLL), an indigenous fruit tree of Nepal. Plant Genetic Resources Newsletter 130: 36-46.

RHOLF, F. J. (1989): NTYSA-PC. Numerical taxonomy and multivariate system, version 2.02j. Applied Biostatistics Incorporation, New York.

Rojas, W., P. BARriga and H. FigueroA (2000): Multivariate analysis of the genetic diversity of Bolivian quinua germplasm. Plant Genetic Resources Newsletter 122: 16-23.

SAmal, S., G. R. Rout and P. C. LenKa (2003): Analysis of genetic relationships between populations of cashew (Anacardium occidentale L.) by using morphological characterization and RAPD markers. Plant Soil and Environment 49 (4): 176-182.

SANwo, J. O. (1980): Correlation coefficient between "fruits" traits as possible aids in the selection of desirable cashew (Anacardium occidentale L.). Nigeria Journal of Science 14 (1): 225-233.

SANwo, J. O. (1979): Cashew germplasm in Nigeria. Annual Report, Cocoa Research Institute of Nigeria, Ibadan, Nigeria, 46-48.

SANwO, J. O. (1974): Report of survey of cashew producing provinces in Nothern Nigerian. Annual Report, Cocoa Research Institute of Nigeria, Ibadan, Nigeria, 101-105.

Sneath, P. H. A. and R. R. Sokal (1973): Numerical taxonomy: The principles and practice of numerical classification. W. H. Freeman and Co., San Fransisco.

Sokal, R. R. and P. H. A. SNeAth (1963): Principle of Numerical Taxonomy. W. H. Freeman and Company, San Francisco. 350pp.

Swamy, K. R. M., L. Thoyajaksha and E.V.V. Bhaskara RAO (2002): Collecting cashew (Anacardium occidentale L.) germplasm from forest plantations in Karnataka, India. Plant Genetic Resources Newsletter 132: 35-38.

Togun, A. (1977): A review of the prospect of Cashew Industry in Nigeria. Cocoa Resaerch Institute of Nigeria, Ibadan, Nigeria. 39pp.

VAlVILOV, N. I. (1951): The Origin, Variation, Immunity and Breeding of cultivated plants. The Ronald Press Company, New York. 40-43.

VENKATARAMAH, T. M. (1976): Cashew nut production and processing - Nigeria agronomic aspect of cashew nut production. Unpublished paper submitted to Cocoa Research Institute of Nigeria. 39pp.

Williams, J. G. K., A. KubeliK, K. J. LivaK, J. A. Rafiski and S. V. TINGEY (1990): DNA polymorphisms amplified by arbitrary primers are useful as genetic markers. Nucleic Acid Research 18: 6351-6355.

Ziegenhagen, B., P. Guillemaut and F. Scholz (1993): A procedure for minipreparations of genomic DNA from needles of silver fir (Abies alba Mill.). Plant Molecular Biology and Reproduction 11: 117-121. 